\title{
Structural Analysis and Optimal Design for Water Tube Panel in an Alkali Recovery Boiler
}

\author{
Zaili Zhao ${ }^{1}$, Jinsheng Xiao ${ }^{2,3}$, Ying Wu ${ }^{4}$, Xiaojun Zhang ${ }^{1}$, Zhiming Wang ${ }^{4}$ \\ ${ }^{1}$ School of Energy and Power Engineering, Wuhan University of Technology, Wuhan, China \\ ${ }^{2}$ School of Automobile Engineering, Wuhan University of Technology, Wuhan, China \\ ${ }^{3}$ State Key Laboratory of Advanced Technology for Materials Synthesis and Processing, \\ Wuhan University of Technology, Wuhan, China \\ ${ }^{4}$ Wuhan Lanxiang Energy \& Environment Protection Technology Co. Ltd., Wuhan, China \\ E-mail: zailizhao@whut.edu.cn \\ Received December 7, 2009; revised February 22, 2010; accepted February 26, 2010
}

\begin{abstract}
Alkali recovery aiming at recovering $\mathrm{NaOH}$ is the best available technology in China's pulp and paper industry; an alkali recovery boiler is a popular one among all alkali recovery units. For the purpose of designing the most reasonable tube-panel of an evaporator in a $1500 \mathrm{t} / \mathrm{d}$ alkali recovery boiler, a total of 8 kinds of cases are put forward for finite element analysis. The modeling, meshing and calculation are carried out for each case. The stress values and their distribution rules are revealed in this paper. The slotting size for the water tubes panel is analyzed by using the optimum design module of ANSYS. After all cases are compared with each other, the optimal one is developed and exemplified in conclusion.
\end{abstract}

Keywords: Alkali Recovery Boiler, Water Tubes Panel, Finite Element, Thermal Stress, Optimum Design

\section{Introduction}

Alkali recovery is the best available and the most economically viable technology for black liquor (BL) from caustic pulping, the predominant process in China (over $70 \%$ ). It can remove most of the COD load, and at the same time recover chemicals and heat to such a great amount that it makes itself economically feasible [1]. So the alkali recovery which includes the processes of $\mathrm{BL}$ evaporation, combustion, green-liquid causticizing and alkali recovery represents an important economic and ecological factor. There are varieties of alkali recovery units which have been using in China's pulp and paper industry at present; the alkali recovery boiler is a most popular one.

The boiler studied by us is a single drum, natural circulation, low odor type alkali recovery boiler. With whole steel, full suspension and full-sealed structure, the gravity of the boiler is withstood by a roof through a boom. The principle of the alkali recovery boiler is that waste water (commonly known as BL) which is discharged after making paper is concentrated as fuel, which is put into the boiler for combustion. Then liquid slag, which is the burning resultant of BL, is discharged from the bottom and recovered into alkali after a causti- cizing process. Alkali recovery boilers are used by paper mills for not only recovering alkali produced by making paper but also generating heat and electricity. Consequently, the purposes of recycling, energy conservation and reducing pollution are achieved. The alkali recovery boiler was originally designed to deal with waste water generated by pulp and recycle cooking alkali, but there are three effect factors for the current alkali recovery boiler: to generate steam by burning organic matter in $\mathrm{BL}$; to generate a green solution for causticizing, reduction of pollutant emission, energy-saving and environmental protection [2].

The difference between model WGZ220/6.8-1 1500 $\mathrm{t} / \mathrm{d}$ alkali recovery boiler [3] and other similar boilers that have already come into use is that, compared with the latter the size of the water tubes panel of alkali recovery boiler in length is extended to somewhat, and the most noticeable difference is that the temperature difference between inlets and outlets of exhaust gas tube rises in a wide range, causing the thermal stress of the tube panel to increase [4]. Therefore structural optimal analysis and safety assessment are quite important for the water tubes panel of evaporators in the boiler.

In order that the boilers are in good condition during long time operation, that there is low stress in stress 
concentration parts of boilers (in places such as the welding seam between the tubes and fins), that the boilers consume fewer materials, and that they are produced and manufactured easily, the structure of the water tubes panel should receive much more attention in design [5]. Generally, there are lots of analytic methods used to carry out structural analysis and optimal design, but a finite element method is a most efficient one [6]. Therefore the finite element method is used to analyze the first stage boiler's evaporator in this paper. Eight kinds of different three-dimensional models for the water tubes panel of the evaporator are proposed and calculated with ANSYS software for getting optimal construction. The optimizing design for obtaining smallest stress of the tube panel is made by analyzing and comparing the stress fields among the 8 kinds of models, and one kind of models is calculated by using the optimized design module of ANSYS software.

\section{Analytic Models and Cases}

\subsection{Geometry Model}

The water tubes panels with a vertical structure which are in membrane type are all hung up to the framework roof through the suspending plate. Each sheet is made up of 22 pieces of $\varnothing 42 \times 5$ tubes through a welding method, and there are fins between the tubes for increasing heat transfer. The distance between two adjacent tubes is $111.5 \mathrm{~mm}$, and all tubes are connected respectively to the upper and lower header. Totally 55 pieces of upper headers together with their water tubes panel are connected to the general header with a bend, as shown in Figure1.

\subsection{Finite Element Model}

In order to calculate and analyze the temperature and stress fields of water tubes panel conveniently, the three-dimensional models set up in the paper have been

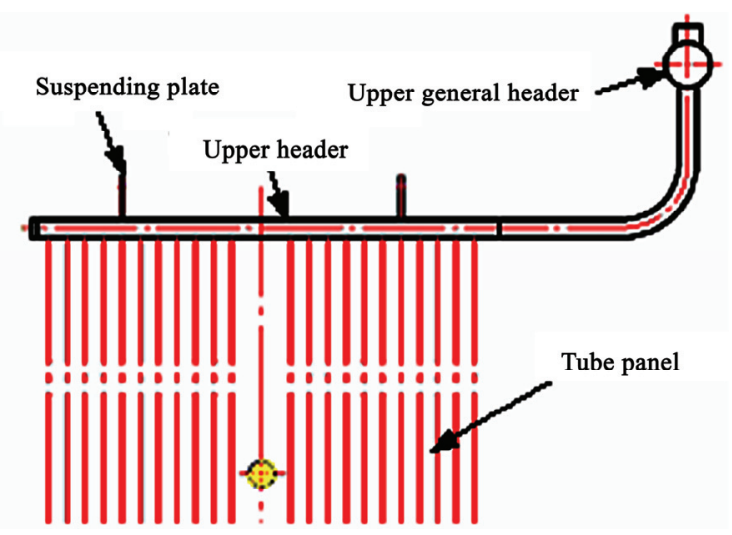

Figure 1. The upper tube panel and headers. simplified as follows [7]:

1) Only a quarter of the whole evaporator is put into research due to its structural symmetry;

2) The welding seams between upper headers and general header are modeled according to their actual dimensions. The welding seams between lower headers and panel tubes have not been taken into account in modeling because of their small size, and consequently calculation is easy. Other small welding seams are to be dealt with similarly;

3) Heat-conducting fins are mounted at the locations which are between every two adjacent tubes in order to increase the heat transfer from the exhaust gas to the water. Only one tube panel is taken into account in modeling because of the same size, material of tubes and fins in each panel. There are locating pins between the panels for locating and separating each panels, and it is not considered for simplifying model;

4) The upper headers are not restricted by the upper general header due to their flexible link, and it is assumed that the upper headers are in symmetrical structure.

The model of the tube panel and its meshing illustration are established as shown in Figure 2 after above simplification. The three-dimensional and 8 nodal SOLID 70 element type is adopted in modeling when temperature field are calculated. The total elements and nodal numbers are 44350 and 70534 respectively in the model of a tube panel. The element type of SOLID 45 is adopted for stress field calculation [8].

In Figure 2(a), there are fins between the tubes; their structural parameters such as thickness of fins, the length of slotting and round radius of the slotting end needs to be chosen and decided in the paper. There is a heatconducting fin with large width which is located between the 11 th and 12 th tubes on the panels, and it is called a middle plate. The middle plate can be designed in a whole or several pieces type according to different cases for stress calculating. The meshing of the tube panel model near the bottom of the suspending plate is shown in Figure 2(b).

\subsection{The Eight Analytic Cases}

In order to find out the distribution rules and try to make sure that the stress of water tubes panel is minimum, the designs with different parameters, such as the fin thickness, the slotting size on the fins and the shapes of the middle plates should be compared with each other and analyzed. Therefore, a total of 8 kinds of cases for the water tubes panel of the first stage evaporator in the paper were proposed. The slotting on the fins contributes is used for reducing the thermal stress in some cases. The slotting size is decided by optimum design module of ANSYS. The detail features and description of them are shown in Table 1. 


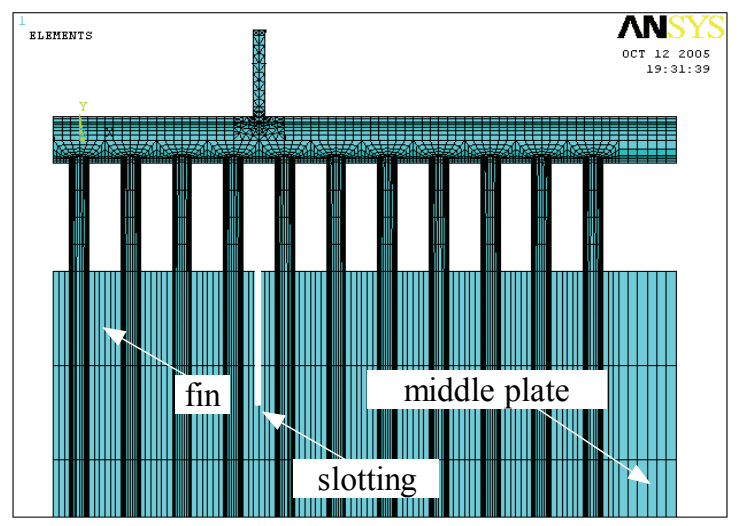

$\begin{array}{lllllllllll}1 & 2 & 3 & 4 & 5 & 6 & 7 & 8 & 9 & 10 & 11\end{array}$

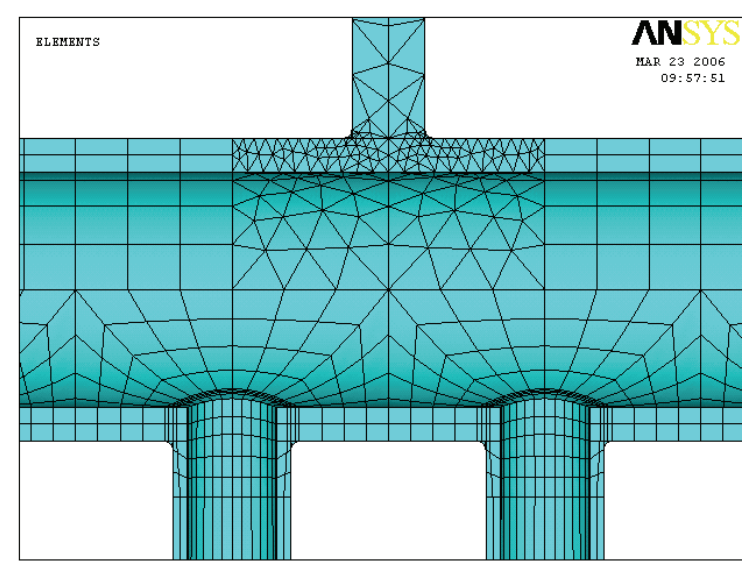

(b) Amplified suspending plate

Figure 2. Modeling and meshing.

Table 1. Descriptions for all cases.

$\begin{array}{ll}\text { Cases } & \text { Descriptions } \\ \text { A } & \text { Fins are not slotted, and the middle plate is taken as an entire plate. } \\ \text { B } & \text { Fins are not slotted, and the middle plate is cut into four pieces. The length of each one is } 600 \mathrm{~mm} . \\ \text { C } & \text { Fins are slotted, but slotting is not staggered, and the description of middle plate is the same as case B. } \\ \text { D } & \text { Only fins between the } 9^{\text {th }} \text { and } 11^{\text {th }} \text { tubes are slotted, and the description of middle plate is the same as case B. } \\ \text { E } & \text { Fins are slotted, slotting is staggered, and the description of middle plate is the same as case B. } \\ \text { F } & \text { Fins are slotted at the upper and lower part, but slotting is not staggered. Fins are slotted at the middle part, and slotting is } \\ \text { staggered. The middle plate is cut into four pieces. The length of each one is } 300 \text { mm. } \\ \text { G } \quad \text { Fins are not slotted, and there is no middle plate. } \\ \text { H } \quad \text { Fins are slotted, but there is no middle plate. }\end{array}$

\section{Structural Parameters \& Boundary Conditions}

\subsection{Structural Parameters}

The structural parameters of the tube panel for the first stage evaporator are shown in Table 2 [9].

\subsection{Boundary Conditions}

The thermal boundary conditions in the evaporator are shown in Table 3 [10].

According to Table 3, the inlet temperature of the exhaust gas is $548.7^{\circ} \mathrm{C}$ and the outlet temperature is $378{ }^{\circ} \mathrm{C}$. The water temperature $\left(295.3^{\circ} \mathrm{C}\right)$ inside tubes is regarded as saturation temperature corresponding to design pres- sure in the boiler drum. When models established by us are calculated by ANSYS software, the value of water pressure is a constant, about $8.15 \mathrm{MPa}$ (it is a design pressure in the boiler drum according to Table 2). The heat transfer coefficient of water and exhaust gas are 5180 and $19.13 \mathrm{~W} /\left(\mathrm{m}^{2 \circ} \mathrm{C}\right)$ respectively [6]. Exhaust gas temperatures at inlet and outlet which are at design values are used for calculation. When exhaust gas flows from the top to the bottom of the tube panel, its temperature will decrease gradually, so the thermal load or temperature applied to the tube panel walls is linear and its inlet and outlet temperatures are accordant with Table 3.

According to the geometry characteristic of model, the Cartesian coordinate system is adopted, with Z-axis standing for the tubes' axial direction and the positive direction pointing to the upper headers [11]. The axial direction of upper headers is taken as the $\mathrm{X}$ direction, 
Table 2. Structural parameters of a tube panel.

\begin{tabular}{ll}
\hline Parameters & Value \\
\hline Rated evaporation capacity & $220 \mathrm{t} / \mathrm{h}$ \\
Rated steam temperature & $480{ }^{\circ} \mathrm{C}$ \\
Heat transfer coefficient & $19.13 \mathrm{~W} /\left(\mathrm{m}^{2}{ }^{\circ} \mathrm{C}\right)$ \\
Tube-sheets numbers & 55 \\
Tube NOS. in each tube panels & 22 \\
Length $\times$ width (the first row) & $22000 \times 2590 \mathrm{~mm}^{2}$ \\
Length $\times$ width (the next row) & $22300 \times 2590 \mathrm{~mm}^{2}$ \\
Distance between two tube panels & $180 \mathrm{~mm}$ \\
Width of middle plate & $111.5 \mathrm{~mm}$ \\
Rated steam pressure & $6.8 \mathrm{MPa}$ \\
Designed steam pressure & $8.15 \mathrm{MPa}$ \\
Size of upper headers & $\varnothing 108 \mathrm{~mm} \times 12 \mathrm{~mm}$ \\
Size of lower headers & $\varnothing 76 \mathrm{~mm} \times 8 \mathrm{~mm}$ \\
Size of upper general headers & $\varnothing 273 \mathrm{~mm} \times 25 \mathrm{~mm}$ \\
Tube material & $20 \mathrm{G} / \mathrm{GB} 5310-1995$ \\
Materials of fins & Q235- A \\
Inner diameter of the tubes & $16 \mathrm{~mm}$ \\
\hline
\end{tabular}

Table 3. Thermal boundary conditions.

\begin{tabular}{lllll}
\hline & $\begin{array}{l}\text { Inlet tem- } \\
\text { peratures } \\
\left({ }^{\circ} \mathrm{C}\right)\end{array}$ & $\begin{array}{l}\text { Outlet } \\
\text { peratures } \\
\left({ }^{\circ} \mathrm{C}\right)\end{array}$ & $\begin{array}{l}\text { tem- } \\
\text { coefficients } \\
\mathrm{W} /\left(\mathrm{m}^{2} \mathrm{C}\right)\end{array}$ \\
\hline $\begin{array}{l}\text { Exhaust gas } \\
\text { Water }\end{array}$ & 548.7 & 378 & 19.13 \\
\hline
\end{tabular}

and the direction from middle plates to the left suspending plate is taken as the positive direction. Y positive direction is decided by $\mathrm{X}$ and $\mathrm{Z}$ axis according to the right hand rule.

Because the evaporator's vertical-horizontal length ratio is too great, only the upper model of the tube panel is shown in Figure3. The panel model is symmetrical in positions of $\mathrm{C}$ and D as shown in Figure 3, so symmetrical constraints are applied to the two positions. The $\mathrm{X}$ direction constraint is applied to section A, i.e. UX in ANSYS. The displacement boundary condition $\left(u_{s}=\right.$ $\bar{u}=0)$ and stress boundary condition $\left(\tau_{y z}=\bar{Z}=0\right)$ in the Z-direction are apparent. The vertical constraint is applied to positions of B which is on top of the suspending plate of the upper header, i.e. UZ in ANSYS [12]. Its displacement boundary condition is $w_{s}=$ $\bar{u}=0$ and its stress boundary condition is $\tau_{x y}=\bar{X}=0$ in the X-direction. The overall weight is withstood by two suspending plates, so the water tubes panel can freely expand in any direction except the upward one.

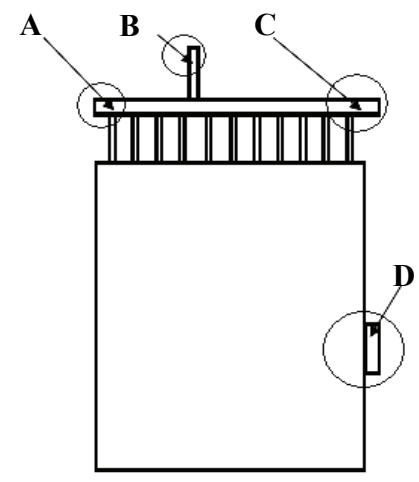

Figure3. Constraints on a tube sheet.

\section{Structural Analysis and Optimization}

\subsection{Optimization for Structural Parameters of the Water Tubes Panel}

In order to ascertain whether the slotting parameters on water tubes panel are correct or not, the optimized calculation is carried out by using ANSYS software; and the results calculated to case D are shown in Figure 4.

In Figure 4 (a), the Y-coordinate stands for the maximum of Von Mises Stress; the X-coordinate stands for the Set Number of iteration [13]. For each set number, there is a set of parameters such as B, R and L. B represents the thickness of the fins, $R$ represents the round radius of the slotting end, and $\mathrm{L}$ represents the slotting length.

In Figure 4 (a), straight line 1 stands for stress setting value, and curve 2 stands for stress which is calculated by using ANSYS software [14]. After careful observation for curves in Figure 4 (a), the curve 2 is found higher than line 1 when Set Number is bigger than 7, so the SET above 7 cannot be regarded as design parameters. In Figure 4 (b), the numbers of curve 3 below SET 5 will cause more volume or weight to be taken. By comparing the results in Figure 4 (a) and (b), the number of SET 7 is chosen as the optimum one. Thus we can get the optimal $\mathrm{B}, \mathrm{L}$ and $\mathrm{R}$, i.e. $\mathrm{B}=3.0814, \mathrm{~L}=696.22$ and $\mathrm{R}=5.0937$.

The results show that the slotting sizes $B, L$ and $R$ adopted in case D are reasonable. As for other cases, structural optimization is also carried out for checking the parameters of the water tubes panel.

\subsection{Structural Analysis and Optimization for Different Cases}

In order to compare the stress in 8 kinds of cases with each other, the tube stress in different cases is shown in Figure 5. The Y-coordinate stands for Von Mises Stress $\left(\sigma_{e}\right)$; the $\mathrm{X}$-coordinate stands for pipe number from the 
left side to the middle plate; the tube serial number can be seen in Figure 2(a). Curve A stands for case A, Curve $\mathrm{B}$ stands for case B, and other curves are expressed in the same way.

The stresses in all cases with the exception of case $\mathrm{G}$ and $\mathrm{H}$, which are not mounted with middle plates, begin to increase gradually from tube 1 to the middle plate as shown in Figure 5. From the Figure 5, the stress of the 11th tube in case $\mathrm{A}$ is the greatest because the middle plates prevent the central tubes from expanding at high temperature. On the contrary, the stress in case $F$ is minimal because the length of the middle plates has been reduced and the slotting on fins is staggered. According to the results calculated, we can conclude that decrease and control of the length of the middle plates or slotting staggered in fins can reduce the maximum stress of the tubes.

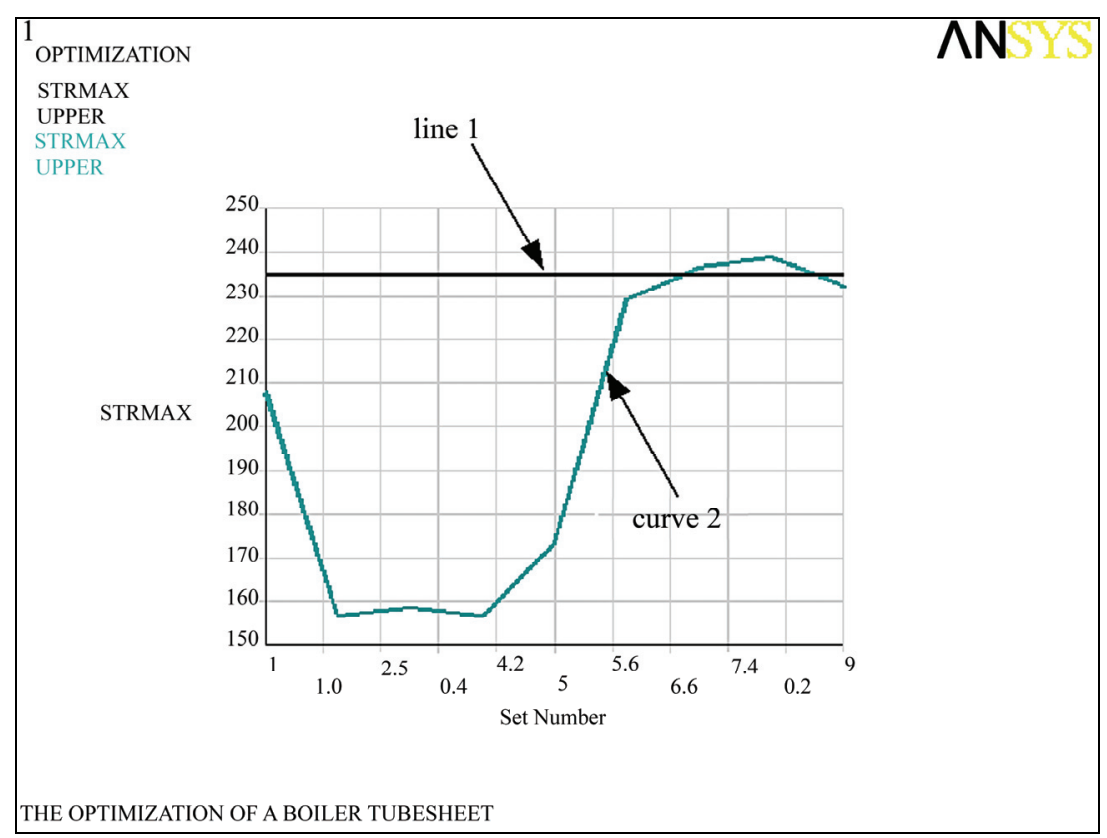

(a) Stress iteration.

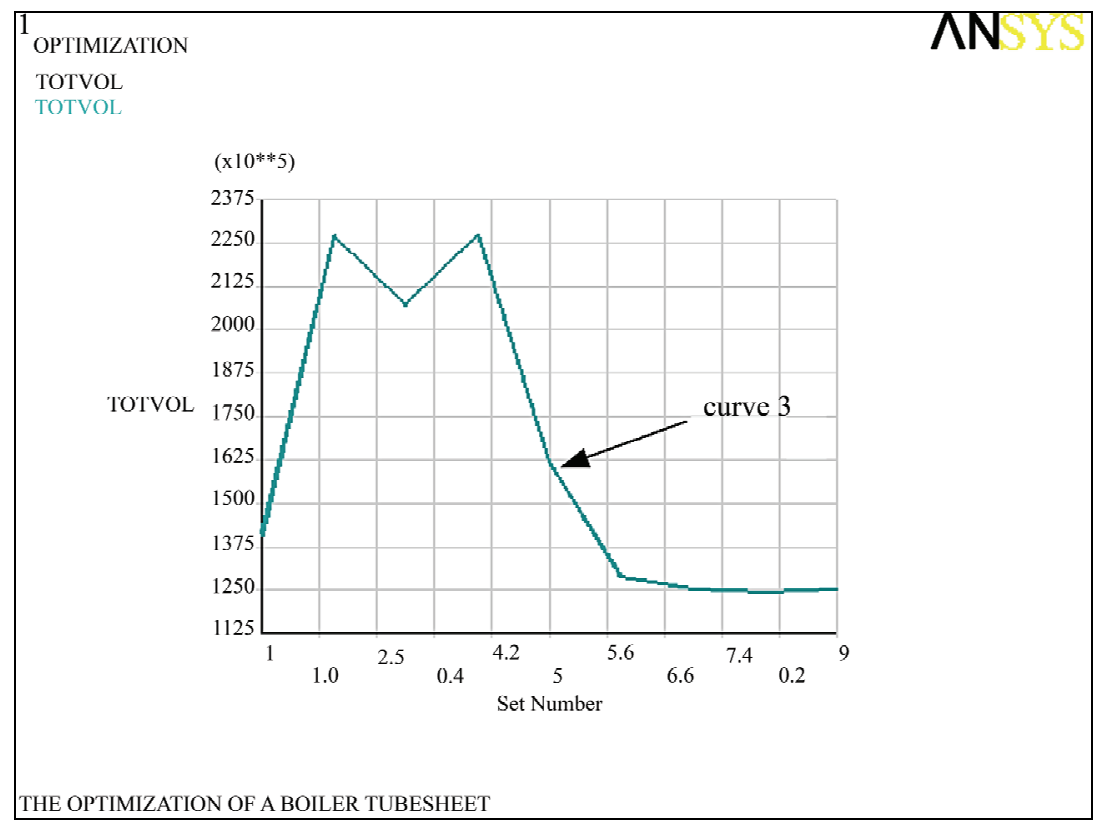

(b) Volume iteration

Figure 4. Structure optimization for slotting on a tube sheet. 

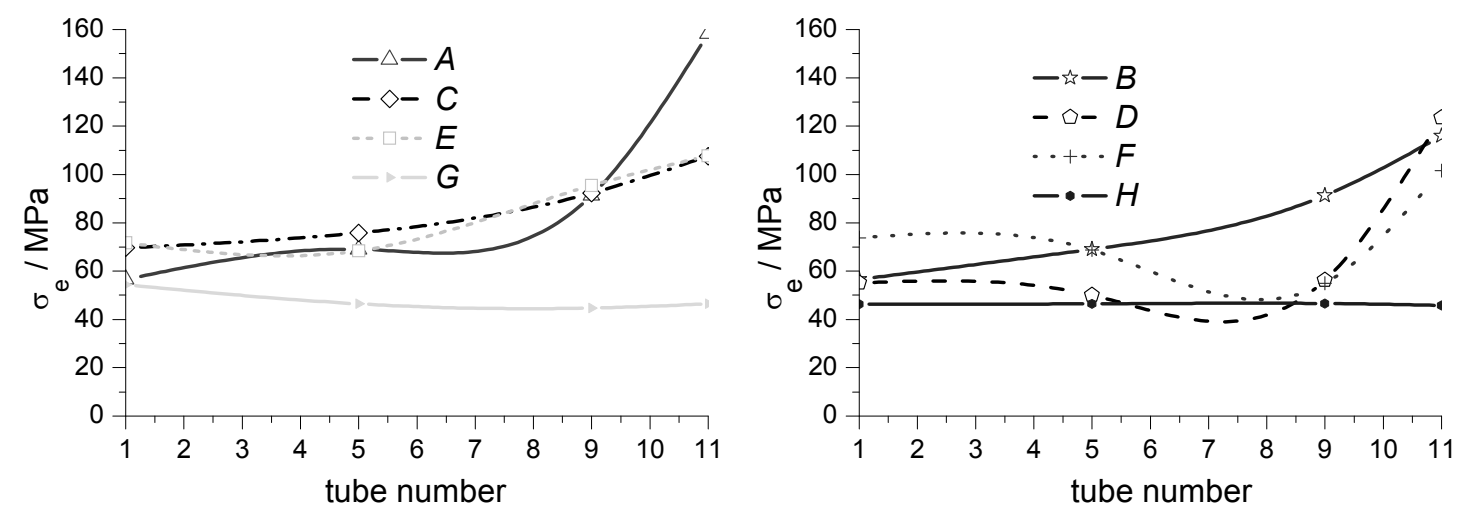

Figure 5. The maximum stress curves of all cases

The middle plate has been cancelled in case $\mathrm{G}$ and case $\mathrm{H}$ in which stresses from tube 1 to tube 11 are relatively low because the water tubes panel can expand freely to both sides in the X-direction. Case G, in which there is no slotting on the fins, is simpler than case H. Therefore, case $G$ is the best one among those cases of boiler evaporators. Comparing with the similar boilers which are used in industry and mostly slotted on the fins, we conclude that if case $G$ is adopted we could not only achieve the same results and simpler manufacture, but also save more materials.

\section{Conclusions}

In order to obtain better recovery of $\mathrm{NaOH}$ and safe operation, the design of water tubes panel in the $1500 \mathrm{t} / \mathrm{d}$ alkali recovery boiler should be considered as follows.

1) In each case, the place of maximum stress is located either at the corner of the middle plate, or at the connection between the tubes and lower header, which is termed as stress concentration. Transition arcs are applied for those places of stress concentration in practical design and manufacture so that the actual stresses are smaller than the calculated values.

2) Among case A, B, C, D, E and F, after maximal Von Mises Stresses on the 11th and 12th tubes are compared with each other, the maximum can be found in case A, the minimum can be found in case F. The stress value in other cases is between the stress value of case $A$ and that of case $\mathrm{F}$.

3) After case B, C, D, E and F are compared with each other, we find that the tube stress in case F is relatively low. The results calculated show that the smaller the length of the middle plate, the less stress in the tube sheet.

4) Among a total of 8 kinds of cases, the manufacture of a water tubes panel without middle plates described in case $G$ is the simplest and the stress level in this case is the lowest. Therefore, case $\mathrm{G}$ is the optimal one.

5) The design parameters of the water tubes panel such as the length of fins and the slotting sizes are considered into the optimal design model, and especially the question of how to choose the staggered slotting should also be taken into account. The final result shows that the proper set such as B, L and R adopted in the cases can be chosen and make it reasonable.

\section{References}

[1] R. Xin, "Cleaner Production in China's Pulp and Paper Industry," Journal of Cleaner Production, Vol. 6, 1998, pp. 349-355.

[2] Z. L. Zhao, Z. F. Yuan, Q. H. Cui and Y. N. Exergy, "Analysis of an WGZ220/6.8-1 Type Alkali Recovery Boiler," Modern Applied Science, Vol. 2, 2010, pp. 23-30.

[3] Z. L. Zhao, "Structure Analysis and Safety Assessment of Pressure Vessels," Ph.D. Thesis, Wuhan University of Technology, Wuhan, 2006.

[4] Z. M. Wang, J. S. Xiao, L. Zang, et al., "Heat Transfer and Thermal Stress Analysis of Heated Water tubes panel in a $1500 \mathrm{t} / \mathrm{d}$ Alkalinity Recycling Boiler," Journal of Wuhan University of Technology, Vol. 28, 2007, pp. $38-40$.

[5] J. S. Xiao, B. Jiang, J. Liu, et al., "Microstructures and Mechanical Properties of Ceramic/Metal Gradient Thermal Barrier Coatings," Journal of Wuhan University of Technology, Materials Science Edition, Vol. 18, 2003, pp. 38-40.

[6] P. S. Ming, J. S. Xiao, J. Liu, et al., "Finite Element Analysis of Thermal Stresses in Ceramic/Metal Gradient Thermal Barrier Coatings" Journal of Wuhan University of Technology, Materials Science Edition, Vol. 20, 2005, pp. 44-47.

[7] A. Saxena, P. K. Liaw, "Remaining Life Estimation of Boiler Pressure Parts-Crack Growth Studies," EPRI Report, CS-4688, 1988.

[8] S. Moaveni, "Finite Element Analysis Theory and Application with ANSYS," 2nd Edition, Publishing House of Electronics Industry, Beijing, 2005, pp. 508-510.

[9] Z. P. Zhu, J. F. Xue, Z. C. Li, et al., "The Common Ma- 
terials for Boiler and Pressure Vessels," Mechanical Industry Publishing House, Beijing, 2004, pp. 1-247.

[10] А. М Гурвич and Н. В. Кузнедов, "Thermal Design of Boiler Units (Standard Method)," China Water Power Press, Beijing, 1960, pp. 52-256.

[11] H. Hayakawa, M. Miyahara, A. Kanaya, et al., "Creepfatigue Life Prediction for Ligament of Boiler Headers by Strain Range Partitioning Method," Journal of the Society of Materials Science, Vol. 48, 1999, pp. 604-609.

[12] A. J. Ramos, C. C. Rios and A. R. Varqas Jesus, "Fatigue
Life Prediction of Delayed Coke Drums," Vision Tecnologia, Vol. 6, 1999, pp. 93-100.

[13] S. S. Manson and G. R. Halford, "Practical Implementation of the Double Linear Damage Rule and Damage Curve Approach or Treating Cumulative Fatigue Damage," International Journal of Fracture, Vol. 17, No. 2, 1981, pp. 169-192.

[14] N. K. Mukhopadhyay and S. G. Chowdhury, "Remaining Life Estimation of a Service Exposed Economizer Tube," Engineering Failure Analysis, Vol. 6, 1996, pp. 233-243. 